\title{
NOTE
}

\section{Can a non-terminal event of the cell cycle be used for phytoplankton species-specific growth rate estimation?}

\author{
Senjie Lin ${ }^{1, *}$, Jeng Chang ${ }^{2}$, Edward J. Carpenter ${ }^{1}$ \\ 'Marine Sciences Research Center, State University of New York, Stony Brook, New York 11794, USA \\ ${ }^{2}$ Institute of Marine Biology, National Taiwan Ocean University, Keelung, 202-24, Taiwan, ROC
}

\begin{abstract}
The cell cycle approach has several advantages over other methods for estimating phytoplankton speciesspecific growth rates in situ. This method has been successfully used in field studies in which the S-G2-M phase was used as a terminal event in the growth rate equation. Recently, the method has been modified, and cell cycle proteins have been substituted as the terminal event marker. Unfortunately, many of these markers represent cell cycle phases other than a terminal event. Whether such a non-terminal event can be used in the cell cycle method will have a great impact on the extent of the application of this method. Our numerical analysis in this report showed that, with the original growth equation, use of a non-terminal event would overestimate the growth rate in most cases. The magnitude of the overestimation increased with the time interval between the non-terminal event and cell division as well as with growth rate. However, by solving an equation derived from existing ones, we were able to eliminate the overestimation. To test the validity of this approach, we simulated 33 populations with different growth rates, levels of synchrony, ratios of the duration of the G2-M phase to that of the $\mathrm{S}$ phase, and shapes of the $\mathrm{S}$ phase fraction curve. Estimates obtained with the $\mathrm{S}$ phase using the new equation were very close to those obtained with the terminal event (the S-G2-M phase) and to true growth rates, with an average underestimation of about $5 \%$ for the 24 rudimentary sımulation cases. We conclude that, with the and of this newly derived equation, a non-terminal event could perform as well as a terminal event in estimating growth rates. Using this approach for field investigation will only require accurately estimatıng the duration of the non-terminal event and the time interval between the non-terminal event and cell division.
\end{abstract}

KEY WORDS: Growth rate - Cell cycle approach Nonterminal event $\cdot$ Phytoplankton P Population simulation

While information on species-specific growth rates of marine phytoplankton is very important for understanding the dynamics of marine phytoplankton populations and communities, such information is relatively limited due to the difficulty in measuring rates. A vari-

•E-mail: selin@ccmail.sunysb.edu ety of approaches have been attempted in the past, each with its own set of limitations (reviewed by Furnas 1990). Recently, an approach based on the concept of the cell cycle has been developed (McDuff \& Chisholm 1982, Carpenter \& Chang 1988). This method is based on the fact that phytoplankton are unicellular organisms and that the completion of each round of the cell cycle results in population growth. The growth rate can then be estimated by monitoring the temporal changes in the percentage of the cells that traverse a phase of the cell cycle leading to mitosis. This method does not require incubation and is free from potential bottle effects (Carpenter \& Chang 1988). Furthermore, cell loss due to grazing (Chang \& Dam 1993), import or export, or death (when it is not cell cycle dependent) does not significantly affect growth rate estimation. Therefore, comparison of this growth rate estimate, a gross growth rate, with net growth rate obtained with cell counts will allow one to estimate rates of cell loss (e.g. van Bleijswijk \& Veldhuis 1995) In addition, the accuracy of the cell cycle method is presumed not to be affected by varying growth conditions.

The first growth rate model of this type (McDuff \& Chisholm 1982) was based on the measurement of frequency of dividing cells in the population (Swift \& Durbin 1972, Swift et al. 1976):

$$
\mu=\frac{1}{n T_{\mathrm{d}}} \sum_{i=1}^{n} \ln \left(1+f_{i}\right)
$$

where $\mu$ is growth rate $\left(\mathrm{d}^{-1}\right) ; n$ is the number of samples collected within a day; $T_{\mathrm{d}}$ is the duration of the cell division; and $f_{\text {, }}$ is the fraction of cells undergoing cell division in the $i$ th sample.

A limitation of this model is that the duration of cell division is usually short and that it is often difficult to monitor the frequency of dividing cells with reason- 
able sampling frequency. This drawback was overcome by using an expanded terminal event consisting of $\mathrm{S}$ (DNA replication), G2 (the interval from S-phase to mitosis), and $M$ phase (mitosis) in place of celldivision phase (Carpenter \& Chang 1988). The terminal event is a segment of the cell cycle which starts anywhere in the cell cycle and ends with cell division and production of daughter cells (Mitchison 1971). Based on a terminal event, the S-G2-M phase, the growth rate equation becomes:

$$
\mu=\frac{1}{n\left(T_{\mathrm{S}}+T_{\mathrm{G} 2 \mathrm{M}}\right)} \sum_{i=1}^{n} \ln \left(1+f_{i(\mathrm{~s})}+f_{i \mid \mathrm{G} 2 \mathrm{M})}\right)
$$

where $T_{\mathrm{S}}$ and $T_{\mathrm{G} 2 \mathrm{M}}$ are the durations of the $\mathrm{S}$ and the G2-M phases, respectively, while $f_{i|\mathrm{~S}|}$ and $f_{|| \mathrm{G} 2 \mathrm{M} \mid}$ are the fractions of cells residing in the S and G2-M phases, respectively. This terminal event was discriminated using cell cycle analysis via DNA quantification (Carpenter \& Chang 1988). Later, the terminal event method was further modified for estimating low growth rates in oligotrophic areas (Vaulot 1992). The DNA quantification method has been used with success to estimate growth rates of phytoplankton cultures and natural populations (e.g. Anita et al. 1990, Chang \& Carpenter 1991, 1994, Yamaguchi 1992, Vaulot et al. 1995).

More recently, taking advantage of rapid advances in understanding biochemical control of the cell cycle (e.g Murray \& Hunt 1993), $\because n$ conducted research aimed at using immunofluorescence of cell cycle related proteins to identify different cell cycle phases for phytoplankton. Such a technique, in comparison to the DNA quantification method, would be simpler in equipment requirement and less time consuming in demarcating a segment of the cell cycle to be used to estimate growth rate. To date, homologs of 3 cell cycle related proteins, proliferating cell nuclear antigen (PCNA; Lin et al. 1994), p34cdc2 (John et al. 1989, Rodriguez et al. 1993, van Dolah et al. 1995, Lin et al. 1996), and cyclin B (Lin et al. 1996), have been identified for phytoplankton. More cell cycle proteins and other biochemical markers may be identified in phytoplankton in the near future. In addition, an immunofluorescence technique with which to visualize the cell cycle proteins has been established recently (Lin \& Carpenter 1996). The potential usctulness of these cell cycle markers for growth rate estimation, however, will depend on how close to cell division their corresponding cell cycle phases are. PCNA, for example, was found to be present in the S-G2-early M phase in some cultures of the marine phytoplankter Dunaliella tertiolecta (Lin et al. 1995). In these cases, the PCNA-phase was close to a terminal event. When it was applied to Eq. (1) in place of the cell division phase, a reasonable growth rate estimate was obtained (Lin et al. 1995).
However, PCNA may be detectable only in the S phase under other growth conditions or in other species (Celis \& Celis 1985, Sasaki et al. 1994, Lin 1995). Before the cell cycle proteins can be widely used for estimating growth rates, it is necessary to address whether the S-phase or another non-terminal event can be used for the existing equations without creating significant errors

In this report, we used the established growth rate equations to assess the nature and magnitude of the error inherent in the use of a non-terminal event such as the $\mathrm{S}$ phase. We also developed a method to eliminate this inherent error. Computer-simulated populations were used to test the validity of the non-terminal event approach.

Materials and methods. Equations: Based on the notion of a terminal event, the growth rate for an asynchronous population can be calculated as follows:

$$
\begin{gathered}
\mu=\frac{1}{T_{\mathrm{G} 2 \mathrm{M}}} \ln \left(1+f_{\mathrm{G} 2 \mathrm{M}}\right) \\
\mu=\frac{1}{T_{\mathrm{S}}+T_{\mathrm{G} 2 \mathrm{M}}} \ln \left(1+f_{\mathrm{S}}+f_{\mathrm{G} 2 \mathrm{M}}\right)
\end{gathered}
$$

Transforming Eqs. (3) \& (4) gives:

$$
f_{\mathrm{S}}=\mathrm{e}^{\mu\left(T_{\mathrm{S}}+T_{\mathrm{C} 2 \mathrm{M})}\right)}-\mathrm{e}^{\mu T_{\mathrm{CIN}}}
$$

Replacing cell division phase with the $\mathrm{S}$ phase for Eq. (1) yields:

$$
\mu_{\mathrm{s}}=\frac{1}{T_{\mathrm{S}}} \ln \left(1+f_{\mathrm{s}}\right)
$$

Eqs. (5a) \& (5b) were used to evaluate the sign and magnitude of errors inherent in the use of the $\mathrm{S}$ phase in the growth rate estimation.

For a partially synchronous population as commonly encountered in laboratory cultures or field samples, simplification was made by assuming that this population was equivalent to an asynchronous population with $f_{\mathrm{S}}$ and $f_{\mathrm{G} 2 \mathrm{M}}$ equaling the means of their fluctuating values in the partially synchronous population. Thus, Eqs. (5a) \& (5b) were still valid with $f_{\mathrm{S}}$ becoming its mean, or $\bar{f}_{\mathrm{s}}$. Rearranging these 2 equations yields:

$$
\mathrm{e}^{\mu\left(T_{\mathrm{S}}+T_{\text {CON }}\right)}-\mathrm{e}^{\mu T_{\text {CIIN }}}-\bar{f}_{\mathrm{S}}=0
$$

Mathematical verification of this equation and the potential error due to the assumption used above are presented in Appendix 1. Using a numerical approach, the true growth rate $\mu$ can be solved from this equation, provided that the averaged S-phase fraction $\left(\bar{f}_{\mathrm{S}}\right)$. the duration of the $\mathrm{S}$ phase $\left(T_{\mathrm{S}}\right)$, and the time interval between the $\mathrm{S}$ phase and cell division (i.e. duration of G2-M phase; $T_{\mathrm{G} 2 \mathrm{M}}$ ) are known. In order to test the validity of this conceptual model, we used known $T_{\mathrm{s}}$ and $T_{\mathrm{G} 2 \mathrm{M}}$ that were set for simulating the populations 
(see below). The value of $\bar{f}_{\mathrm{S}}$ was obtained also from the simulated populations in this report. In reality, where the time interval between 2 consecutive samples is not constant, $\bar{f}_{\mathrm{S}}$ should be calculated as time-weighted average. In our computation, tentative values of $\mu$ were given starting from 0.693 ( 1 doubling $\mathrm{d}^{-1}$ ) and stepping up or down by 0.00001 for each iteration. The tentative value was recognized as a true growth rate when it gave the left-hand side of Eq. (6) a value between -0.00001 and 0.00001 .

Population simulation: Populations with different growth rates were simulated to test the trends predicted by the equations shown above. Simulated populations were constructed following a previously published approach (Chang \& Carpenter 1990). In the 24 rudimentary cases the ratio of $T_{\mathrm{G} 2 \mathrm{M}}$ to $T_{\mathrm{S}}$ was varied between 0.16 to 13.5 with a fixed total duration, $T_{\mathrm{S}}+T_{\mathrm{G} 2 \mathrm{M}}$, equaling $14.5 \mathrm{~h}$. Variation of $T_{\mathrm{S}}$ was intended to represent a selection of different phases in the cell cycle as a quasi-terminal event. In simulation, growth rates were varied from 0.25 to $0.91 \mathrm{~d}^{1}$ by changing parameter $A$ of the model described in Chang \& Carpenter (1990). To test whether different levels of synchrony of the population would affect the outcome of the estimation, 3 additional rudimentary populations were constructed with similar growth rates $(0.685$ to $0.692 \mathrm{~d}$ ') but different synchrony levels. Another 6 populations were simulated with a left-skewed, right-skewed, and a doubled peak S phase (Chang \& Carpenter 1990). Two sets of $T_{\mathrm{S}}$ and $T_{\mathrm{G} 2 \mathrm{M}}$ were used for the 3 cases: $T_{\mathrm{S}}=2 \mathrm{~h}$, $T_{\mathrm{G} 2 \mathrm{M}}=12.5 \mathrm{~h}$, and $T_{\mathrm{s}}=7 \mathrm{~h}, T_{\mathrm{G} 2 \mathrm{M}}=7.5 \mathrm{~h}$. In all cases, phase fractions (i.e. fraction of cells that were residing in a certain phase) for the S, G2, and M phases were collected every $2 \mathrm{~h}$ for a $24 \mathrm{~h}$ period, when the populations were stable at the end of the simulation period.

Computation of growth rates: True growth rates for the simulated populations were produced at the end of the simulation; they were calculated from cell numbers, $\mu=\left(\ln N_{2}-\ln N_{1}\right) /\left(t_{2}-t_{1}\right)$, where $N_{2}$ and $N_{1}$ were cell concentrations at times $t_{2}$ and $t_{1}$, respectively. Estimates of the growth rates were obtained using 2-hourly phase fractions and known phase durations. The $\mathrm{S}$ phase was applied to Eq. (1) whereas the terminal event S-G2-M phase was applied to Eq. (2), to produce growth rate estimates ( $\mu_{\mathrm{S}}$ and $\mu_{\mathrm{Sc}, 2 \mathrm{M}}$, respectively). Meanwhile, the mean of the $13 \mathrm{~S}$-phase fractions for each population $\left(\bar{f}_{s}\right)$ was computed and applied, with $T_{\mathrm{G} 2 \mathrm{M}}$ and $T_{\mathrm{S}}$, to Eq. (6) to obtain another estimate $\left(\mu \varsigma^{\text {c }}\right)$.

Results. Combining Eqs. (5a) \& (5b) gave a new equation indicating that $\mu_{\mathrm{s}}$ is always greater than $\mu$. This demonstrated that use of the $\mathrm{S}$ phase as a quasiterminal event would always overestimate the true growth rates that are obtainable using a strict terminal event. The equation also indicated that the overestimation increased when the true growth rate or $T_{\mathrm{G} Z \mathrm{M}}$ increased (Fig. 1). The maximum potential error, corresponding to growth rates from 0.25 to $0.91 \mathrm{~d}^{-1}$, and $T_{\text {Gi2M }}$ from 0 to $70 \mathrm{~h}$, ranged between 0 and $90 \%$

In the 24 rudimentary cases of simulation, 4 partially synchronous populations were constructed for each growth rate, with different durations for each cell cycle phase. The time serial profiles of phase fractions varied among the 4 populations (Fig. 2). In cases where growth rate was smaller than $0.25 \mathrm{~d}^{-1}$, or when the ratio of $T_{\mathrm{G} 2 \mathrm{M}}$ to $T_{\mathrm{S}}$ was smaller than 0.21 with growth rates lower than $0.89 \mathrm{~d}^{-1}$, use of the $\mathrm{S}$ phase directly with the original equation, Eq. (1), produced estimates close to true growth rates (Fig. 3A, Table 1). However, overestimation of growth rates was apparent in other cases (Fig. 3A). The results confirmed that the overestimation was greater for higher growth rates or higher ratios of $T_{\mathrm{G} 2 \mathrm{M}}$ to $T_{\mathrm{S}}$ (Fig. $3 \mathrm{~A}$, Table 1). In addition, the overestimation was aggravated by low synchrony of the population (Fig. 4). The overestimation contrasted with the slight underestimation occurring when a terminal event, the S-G2-M phase, was used (Fig 3C).

Use of Eq. (6) eliminated the overestimation in all the 24 populations with a ratio of $T_{\mathrm{G} 2 \mathrm{M}}$ to $T_{\mathrm{S}}$ ranging from 0.21 to 13.5 (Fig 3B). In fact, all estimates after this adjustment with Eq. (6) shifted from overestimation to underestimation. The magnitude of the underestimation appeared to increase slightly with the broad increase in the ratio of $T_{G 2 M}$ to $T_{S}$. Nevertheless, the absolute values of errors in the estimates were reduced significantly, from original $14.04 \% \pm 16.03 \%$ to $5.29 \%$ $\pm 1.65 \%$ This error was not significantly different from the error occurring when the terminal event, the S-G2-M phase, was used (Table 1).

Even with an unfavorable ratio of $T_{\mathrm{G} 2 \mathrm{M}}$ to $T_{\mathrm{S}}$ (6.25), variability of the synchrony level did not seem to cause significant differences in the accuracy of growth rate estimation using Eq. (6), although the higher synchrony level tended to slightly worsen the underestimation (Fig. 4). Over all the 3 different synchrony levels, original overestimation was eliminated and reasonable growth rate estimates were achieved. In contrast, in the 6 special cases with right-skewed, left-skewed, and doubled peak $\mathrm{S}$ phase, growth rate estimates were severely overestimated (Fig. 5A). Such overestimation cannot be reduced to a satisfactory level using Eq (6) (Fig. 5B).

Discussion. The major source of the overestimation associated with the use of a non-terminal event, such as the $\mathrm{S}$ phase, is probably that the completion of such a phase is not immediately followed by cell division. Rather, a time interval exists between the completion of this phase and cell division. After the non-terminal event, therefore, the total cell number used to calculate the phase fraction does not increase as it would when a terminal event is used. Hence, the phase fractions would generally be overestimated. Consequently, the 


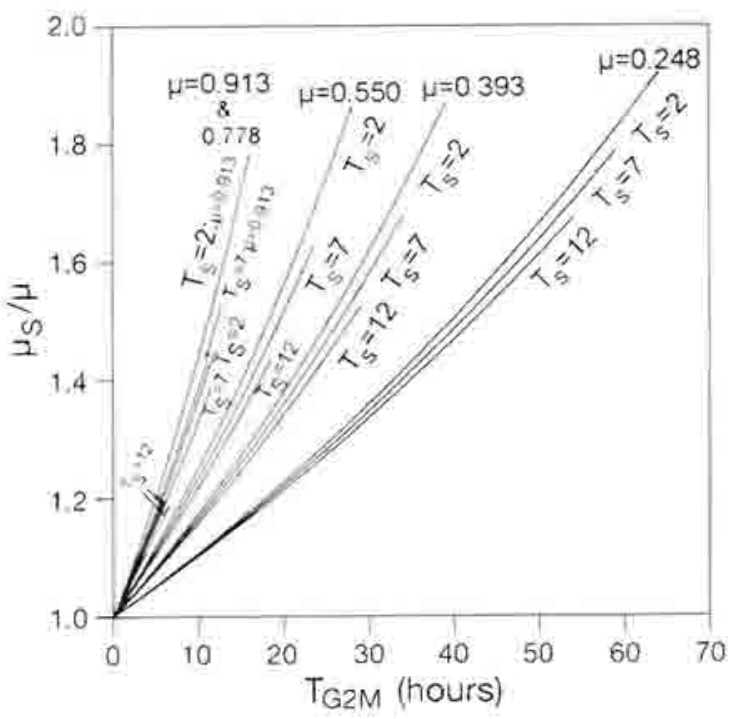

Fig, 1. Relationship between overestimation of growth rates associated with use of the $S$ phase and the duration of the 62 -

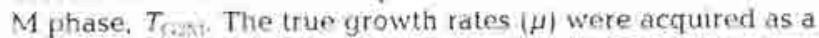
result of population simulation (see Table 11 , whereas the growth rate astimated using the $\mathrm{S}$ phase $\left(\mu_{\mathrm{s}}\right)$ was computed using Eqs. $(5 \mathrm{a})$ \& (5b): The duration of the $\mathrm{S}$ phase $\left(T_{s}\right)$ was varied from 12,7, to $2 \mathrm{~h}$. Each curve was drawn to the possible. maximum $T_{\text {C2M }}$ under its corresponding growth rate li.e. $T_{\mathrm{s}}+$ $\left.T_{\mathrm{G} 2 \mathrm{~N}}=24 \times(0,693 / \mu)\right]$

Table 1 . Results of growth rate estimation $\mu_{\mathrm{S}}$ is the growth tate estimated using the $\mathrm{S}$ phase, $\mu_{\mathrm{S}}$ is the adjusted $\mu_{\mathrm{Si}} \mu_{\mathrm{S}}$ is is the growth rate estimaled using the termunal event. the S-G2-M phase Error 1. Error 2, and Error 3 are the errors associated with $\mu_{\mathrm{s}}, \mu_{\mathrm{s}}{ }^{\mathrm{a}}$, and $\mu_{\mathrm{su}}$, respectively

\begin{tabular}{|c|c|c|c|c|c|c|c|}
\hline $\begin{array}{l}\text { Truis } \mu \\
\left(\mathrm{d}^{=1}\right)\end{array}$ & ${ }_{(\mathrm{d})}^{\mu_{1}}$ & Error 1 & $\begin{array}{l}\mu^{0} \\
\left(\mathrm{~d}^{-1}\right)\end{array}$ & $\begin{array}{c}\text { Error } 2 \\
(0,1)\end{array}$ & 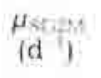 & $\begin{array}{c}\text { Error } 3 \\
\text { (1) }\end{array}$ & $\begin{array}{l}\text { Ratio of } \\
T_{\text {Cast to } T_{5}}\end{array}$ \\
\hline 0.248 & 0.242 & -2.38 & 0.240 & -319 & 0.241 & -2.86 & 0.21 \\
\hline 0.248 & 0.245 & -1.17 & 0.233 & -6.05 & 0.241 & -2.86 & 1.07 \\
\hline 0.248 & 0.256 & 3.39 & 0.230 & -7.38 & 0.241 & -2.86 & 6.25 \\
\hline 0.248 & 0.260 & 4.52 & 0.229 & -7.54 & 0.241 & -2.86 & 13.50 \\
\hline 0.393 & 0.385 & -2.11 & 0.381 & -3.16 & 0.378 & -3.72 & 0.21 \\
\hline 0.393 & 0.400 & 1.88 & 0.371 & -5.67 & 0.378 & -372 & 1.07 \\
\hline 0.393 & 0.433 & 10.15 & 0.364 & -7.28 & 0.378 & -3.72 & 6.25 \\
\hline 0.393 & 0.442 & 12.34 & (1) 363 & -7.56 & 0.378 & -372 & 13.50 \\
\hline 0.550 & 0.540 & -1.87 & 0.534 & -2.84 & 0.524 & $-4,65$ & 0.21 \\
\hline 0.550 & 0.579 & 5.33 & 0.524 & -4.76 & 0.524 & -465 & 1,07 \\
\hline 0.550 & 0.650 & 18.13 & 0.513 & -680 & 0.524 & -4.63 & 6.25 \\
\hline 0.5 .50 & 0.669 & 21.65 & 0.510 & -7.24 & 0.524 & -4.65 & 13.50 \\
\hline 0.778 & 0.764 & -1.75 & 0.760 & -2.37 & 0725 & -6.86 & 021 \\
\hline 0.778 & 0.849 & 9.11 & 0.746 & -4.09 & 0.725 & -6.86 & 1.07 \\
\hline 0.778 & 0.998 & 28.25 & 0.729 & -6.25 & 0.725 & -6.86 & 6.25 \\
\hline 0.778 & 1.052 & 35.25 & 0.727 & -6.57 & 0.725 & -6.86 & 13.50 \\
\hline 0.888 & 0.895 & 0.77 & 0.860 & -317 & 0.838 & -5.69 & 0.21 \\
\hline 0.888 & 1.008 & 13.50 & 0.845 & -485 & 0.838 & -5.69 & 1.07 \\
\hline 0.888 & 1.209 & 36.15 & 0.838 & -5.69 & 0.838 & -5.69 & 6.25 \\
\hline 0.888 & 1.287 & 44.88 & 0.839 & -5.52 & 0.838 & $-5,69$ & 13.50 \\
\hline 0.913 & 0.92 .5 & 1.30 & 0.884 & -3.22 & 0864 & -5.41 & 0.21 \\
\hline 0.913 & 1.046 & 14.57 & 0.868 & -4.96 & 0.864 & -541 & 107 \\
\hline 0913 & 1.261 & 38.08 & 0.863 & -5.53 & 0.864 & $-5.4 !$ & 6.25 \\
\hline 0.913 & 1.343 & 47.06 & 0.864 & -5.32 & 0864 & -541 & 13.50 \\
\hline Mean & & 14.04 & & -5.29 & & -4.87 & \\
\hline SD & & 16.03 & & 1.65 & & 1.34 & \\
\hline
\end{tabular}

overestimation was aggravated by elongation of $T$ iamt The G2 phase is 1 of the 2 control points of the cell cycie; its duration varies with growth conditions such as temperature and nutrient availability fOlson et al. 1986). Therefore, the error in the growth rate estimates caused by applying a non-terminal event preceding the $\mathrm{G} 2$ phase to the original growth rate model may vary with growth conditions.

Fortunately; with the aid of Eq (6), the overestimation associated with the use of a non-terminal event such as the $S$ phase can be eliminated. This elimination was achieved for all rudimentary simulated populations examined with widely different ratios of $T_{\text {Cin }}$ to $T$. The usability of this equation for differing ratios of $T_{L_{2}}$ to $T_{\mathrm{S}}$ suggests that different non-terminal events, virtually any section of the cell cycle, can be used for growth rate estimation. When $T_{\mathrm{C} 2 \mathrm{~N}}$ is $0, \mathrm{Eq}$. (6) shows that $\mu$ equals $\mu_{\mathrm{S}}$ thus reducing this method to the original terminal event-based equation Eq. (2). This flexibility in the selection of a cell cycle event will facilitate growth rate estimation. With advances in cell cycle studies more cell cycle markers, including cell cycle proteins, will be identified. One will have greater ability to select a cell cycle marker that is easy to detect For example, PCNA is a highly conserved protein and is likely to occur in all phytoplankton (Lin et al. 1994, Lin 1995). It is thus a promising cell cycle marker for phytoplankton growth rate estimation. In some cell types, PCNA has been found to be restricted to the S phase (Celis \& Celis 1985, Sasakı et al 19941 and hence is not a marker of a terminal event. The same was suggested for some cultures of phytoplankton where the use of PCNA immunofluorescence for previous growth rate equations overestimated growth rates (Lin 1995) However. the present numerical analysis suggests that with the aid of Eq. (6) the PCNA method can now be used without overestimation.

The consequent underestimation of growth rates was probably attributable to the derivation of Eq. (6), including the assumption regarding the equivalence of a partially synchronous to an asynchronous population. Since $\sum \sigma_{i}^{2}$ is never 0 for a partially synchronous population, there always exists an error isee Appendix 1). This can explain why the error in the growth rate is somewhat higher for populations of medium and high synchrony than populations of low synchrony (Fig 4) However, although 


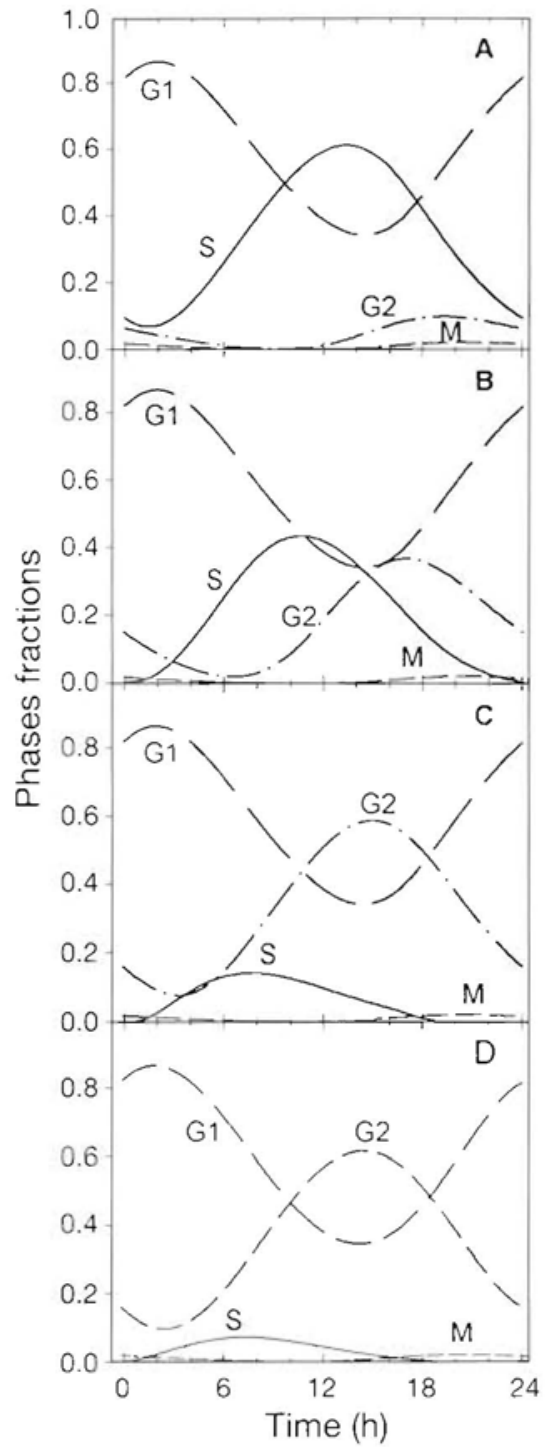

Fig. 2. Typical time serial profıles of phase fractions for populations with different phase durations. Growth rate was $055 \mathrm{~d}^{-1}$ for all 4 populations. (A) $T_{\mathrm{S}}=12 \mathrm{~h} ; T_{\mathrm{G} 2}=2 \mathrm{~h} ; T_{\mathrm{M}}=$ $05 \mathrm{~h}$. (B) $T_{\mathrm{S}}=7 \mathrm{~h} ; T_{\mathrm{C} 2}=7 \mathrm{~h} ; T_{\mathrm{N}}=0.5 \mathrm{~h}$. (C) $T_{\mathrm{S}}=2 \mathrm{~h} ; T_{\mathrm{C} 2}=12 \mathrm{~h}$; $T_{\mathrm{M}}=0.5 \mathrm{~h}$. (D) $T_{\mathrm{\varsigma}}=1 \mathrm{~h}: T_{\mathrm{G} 2}=13 \mathrm{~h} ; T_{\mathrm{M}}=0.5 \mathrm{~h}$

not mathematically obvious, this error is normally small in real estimation. As shown in Table 1, the average error for the 24 rudimentary cases was about $5 \%$, which was comparable to the error arising from the terminal event (S-G2-M phase) approach.

Similar to the case of using the terminal event, S-G2M, growth rate estimates obtained with the nonterminal event were very different from true growth rates when the population had a left-skewed, rightskewed, or doubled peak S-phase fraction curve. Even with Eq. (6) the drastic overestimation, albeit reduced to some extent, cannot be eliminated. The overestimation inherent in the left-skewed and right-skewed pop-

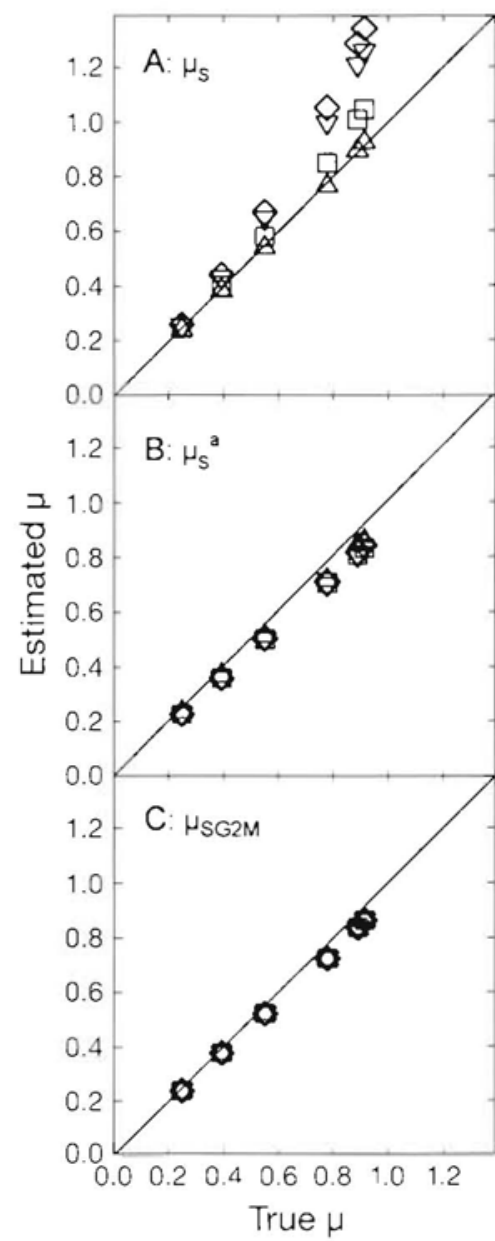

Fig. 3. Relationship between estimated and true growth rates for 24 simulated rudımentary populations. (A) The S phase was applied as a quasi-terminal event to Eq. (1) to produce growth rate estimates. (B) Mean S-phase fraction $\left(\bar{f}_{\mathrm{S}}\right)$ along with known $T_{\mathrm{S}}$ and $T_{\mathrm{G} 2 \mathrm{M}}$ was applied to Eq. (6) to produce growth rate estimates. (C) The S-G2-M phase was used as a terminal event and applied to Eq. (2) to produce estimates Symbols: $(\Delta) T_{\mathrm{S}}=13 \mathrm{~h}, T_{\mathrm{G} 2 \mathrm{M}}=1.5$; (ㅁ) $T_{\mathrm{S}}=7 \mathrm{~h}, T_{\mathrm{G} 2 \mathrm{M}}=7.5 \mathrm{~h}$;

( $\nabla) T_{\mathrm{h}}=2 \mathrm{~h}, T_{\mathrm{C}: 2 \mathrm{M}}=12.5 \mathrm{~h} ;(\diamond) T_{\mathrm{S}}=1 \mathrm{~h}, T_{\mathrm{G} 2 \mathrm{M}}=13.5 \mathrm{~h}$

ulations is because in these cases, the assumption for the cell cycle method that the phase fraction curves are symmetrical about its mode or bell-shaped was not fulfilled (Carpenter \& Chang 1988) The error in the case of double-peak $\mathrm{S}$ phase derives from the violation of the assumption that a phase fraction has only a single maximum over the sampling period (Carpenter \& Chang 1988). This suggests that the assumptions for the terminal-event-based cell cycle approach also need to be met for the non-terminal-event-based cell cycle method. Fortunately, the 3 cases of S-phase style are not common; in natural phytoplankton populations the bell-shaped S-phase fraction is dominant, which can be seen from previous investigation (e.g. Chang \& Carpenter 1991, Vaulot et al. 1995) 


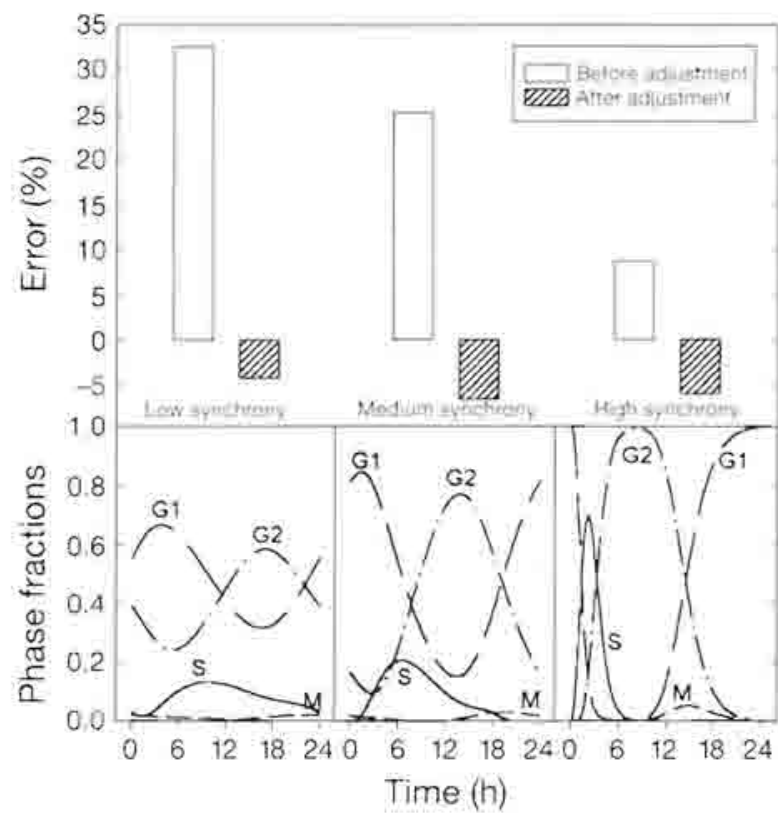

Fig. 4. Effect of population synchrony on the error of growth rate estumates. Upper panel Overestimation inherent in the use of the S phase for Eq (1) decreased when synchrony increased In contrast; underestimation inherent in the use of Eq. (6) increased slightly with the level of synchrony. Lower panel: Time senal protiles of the cell cycle phase fractions corresponding to 3 different synchrony levels. From left to right: are low svnchrony, medium synchrony, and high synchtony

Successful application of this non-terminal event approach will depend on 2 major factors. First, the duration of the non-terminal event and the time interval between the non-terminal event and cell division have to be known: With DNA quantification and the cell cycle analysis technique (Carpenter \& Chang 1988) the duration of each phase can be estimated in situ with reasonable accuracy. In the non-terminal event approach the duration cannot be obtained in the same way. Recently we adapted a graphic method (Takahashi 1966), deriving the duration from the time interval between the 2 median points of the 2 slopes of the phase fraction curve (Lin et al. 1995, Lin \& Carpenter 1995) Using this method, the duration of the non-terminal event can be obtained. Similarly, the duration of the $M$ phase can be obtained by staining the nucleus with 4:6-diamidino2-phenylindole (DAPI), examining double-nucleated cells, and constructing an M-phase fraction curve The interval between the non-terminal event and the $M$. phase can then be calculated. However, the graphic method may overestimate the duration especially when the synchrony of cell cycle progression is low. although most populations adapted to natural light dark cycles appeared to be farly synchronous (Chisholm 1981) The applicability of this graphic method needs to be tested, and a different way may be desirable and is under study in our laboratory.

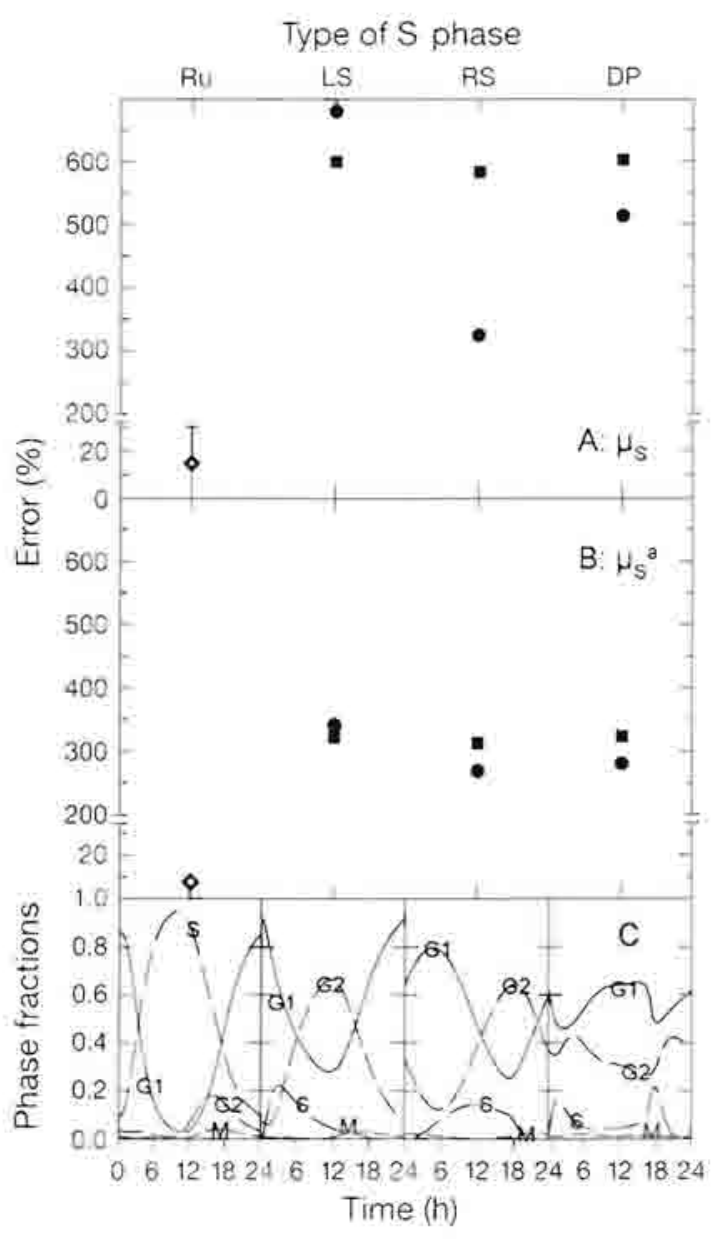

Fig 5. Comparison of telative errors in growth rate estumates between the mdimentary and 6 special cases X-axis labels: $\mathrm{Ru}=$ rudimentary; $\mathrm{LS}$ = left-skewed peak of the $\mathrm{S}$ phase; $\mathrm{RS}=$ tight-skewed peak of the S phase: $\mathrm{DP}=$ doubled peak of the $\mathrm{S}$ phase. (A) Estimates were made using Eq. (11) (B) Estimates made using Eq 161 . Dots and squares represent populations with $T_{\mathrm{S}}=7 \mathrm{~h}, T_{\mathrm{s}}=7.5 \mathrm{~h}$ and $T_{\mathrm{S}}=2 \mathrm{~h}, T_{\text {ene }}=12.5 \mathrm{~h}$ respectively, (C) Tine serial profiles of phase tractions corresponding to the 4 cases

Second, the between-researcher variation in estimating phase fractions should be minimized The variation may be rather considerable when an immunofluorescence technique is used to detect the marker of the non-terminal event, and when the scoring of the staining is performed manually. This variability may be minimized by strictly following a well-established immunostaining and scoring protocol. The magnitude of the resultant error in growth rate estimates warrants further testing with laboratory cultures.

Acknowledgements: We are grateful to Dr D Vaulot for his cutical comments on our previous articles that inspired out thinking on this topic and helpful discussion about this manuscript This resedrch is partally supported by NSF grant OCE 9529970 and by a National Sconce Coundi (ROCl grant NSC 86-2313-8-019-025: 
Appendix 1. Verification of Eq. (6)

On the one hand, by using the Taylor expansion, Eq. (6) can be transformed to:

$$
1+\mu\left(T_{\mathrm{S}}+T_{\mathrm{G} 2 \mathrm{M}}\right)+\left[\mu\left(T_{\mathrm{S}}+T_{\mathrm{G} 2 \mathrm{M}}\right)\right]^{2}-\left[1+\mu T_{\mathrm{G} Z \mathrm{M}}+\left(\mu T_{\mathrm{C} Z 2 \mathrm{M}}\right)^{2}\right]=\bar{f}_{\mathrm{S}}
$$

which can be reduced to:

$$
\mu T_{\mathrm{S}}+\left(T_{\mathrm{S}}^{2}+2 T_{\mathrm{S}} T_{(\mathrm{C} 2 \mathrm{M})} \mu^{2}=\bar{f}_{\mathrm{S}}\right.
$$

On the other hand, for a partially synchronous populatıon Eqs. (3), (4) \& (5a) are all valid for a growth rate taken at a time point or tor the 1 th sample (McDuff \& Chisholm 1982). Performing Taylor expansion for the right-hand side terms of Eq. (5a) yields:

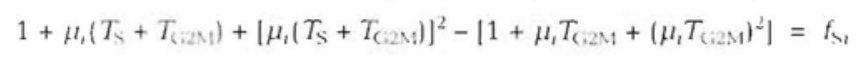

which can be reduced to:

$$
\mu_{1} T_{\mathrm{S}}+\left(T_{\mathrm{S}}^{2}+2 T_{\mathrm{S}} T_{(, 2 \mathrm{~N})}\right) \mu_{t}^{2}=f_{S t}
$$

By summing up all $n$ samples for each term of the equation over a sampling penod and taking the average (McDuft \& Chisholm 1982), we have:

$$
\begin{gathered}
T_{\mathrm{S}}\left(\frac{1}{n} \sum_{i=1}^{n} \mu_{i}\right)+\left(T_{\mathrm{S}}^{2}+2 T_{\mathrm{S}} T_{\mathrm{G} 2 \mathrm{M}}\right)\left(\frac{1}{n} \sum_{i=1}^{n} \mu_{i}^{2}\right)=\frac{1}{n} \sum_{i=1}^{n} f_{\mathrm{S}_{1},} \text { or } \\
\mu T_{\mathrm{S}}+\left(T_{\mathrm{S}}^{2}+2 T_{\mathrm{S}} T_{\mathrm{G} 2 \mathrm{M}}\right)\left(\frac{1}{n} \sum_{i=1}^{n} \mu_{i}^{2}\right)=\bar{f}
\end{gathered}
$$

Assuming $a_{1}$ is the difference between $\mu$, and $\mu$, 1.e.

Eq. (A2) can be re-arranged to the following:

$$
\mu_{i}=\mu+a_{i} \text {, where } \sum_{i=1}^{n} a_{i}=0
$$

$$
\mu T_{\mathrm{S}}+\left(T_{\mathrm{S}}^{2}+2 T_{\mathrm{S}} T_{\mathrm{G} 2 \mathrm{M}}\right)\left(\mu^{2}+\frac{1}{n} \sum_{i=1}^{n} \mathrm{~d}_{i}^{2}\right)=\bar{f}
$$

Eqs. (A3) and (A.1) are formally the same, with the former having an extra term, $\frac{1}{n} \sum_{i=1}^{n} a_{t}^{2}$. For an asynchronous population where this term equals 0 , both equations are exactly the same. For a partially synchronous population the difference between Eq. (A1) and Eq. (A3) increases with the level of synchrony. For populations with phase fraction curves of bell-shape as encountered most frequently in nature, the value of this extra term should be relatively small.

\section{LITERATURE CITED}

Anita AN, Carpenter EJ, Chang J (1990) Species-specific phytoplankton growth rates via diel DNA snythesis cycles. III. Accuracy of growth rate measurement in the dinoflacgellate Prorocentrum minımum. Mar Ecol Prog Ser 63:273-279

Carpenter E.J. Chang J (1988) Species specific phytoplankton growth rates via diel DNA synthesis cycles. I. Concept of the method. Mar Ecol Prog Ser 43:105-111

Celis JE, Celis A (1985) Cell cycle-dependent variations in the distribution of the nuclear protein cyclin proliferating cell nuclear antigen in cultured cells: subdivision of S-phase. Proc Natl Acad Sci USA 82:3262-3266

Chang J, Carpenter EJ (1990) Species-specific phytoplankton growth rates via diel DNA synthesis cycles. IV. Evaluation of the magnitude of error with computer-simulated cell populations. Mar Ecol Prog Ser 65:293-304

Chang J, Carpenter EJ (1991) Species-specific phytoplankton growth rates via diel DNA synthesis cycles. V. Application to natural populations in Long Island Sound. Mar Ecol Prog Ser 78:115-122

Chang J, Carpenter EJ (1994) Active growth of the oceanic dinoflagellate Ceratium teres in the Caribbean and Sargasso Sea estimated by cell cycle analysis. J Phycol 30: 375-381
Chang J, Dam HG (1993) The influence of grazing on the estimation of phytoplankton growth rate via cell cycle analysis: modeling and experimental evidence. Limnol Oceanogr 38:202-212

Chısholm SW (1981) Temporal pattern of cell divisıon in unicellular algae. In: Platt T (ed) Physiological bases of phytoplankton ecology. Can Bull Fish Aquat Sci 210:150-181

Furnas MJ (1990) In situ growth rates of marine phytoplankton: approaches to measurement, community and species growth rates. J Plankton Res 12:1117-1151

John PCL. Sek FJ, Lee MG (1989) A homolog of the cell cycle control proteın p34cdc2 participates in the division cycle of Chlamydomonas and a similar protein is detectable in higher plants and remote taxa. Plant Cell 1 1185-1193

Lin S (1995) Studies on three cell cycle proteins (PCNA, p34cdc2, and cyclin B) as potential cell cycle markers for estımatıng species-specific growth rates of marine phytoplankton. PhD dissertation, State University of New York at Stony Brook

Lin S, Carpenter EJ (1995) Growth characteristics of marine phytoplankton determined by cell cycle proteins: the cell cycie of Ethmodiscus rex (Bacillanophyceae) in the southwestern North Atlantic Ocean and Caribbean Sea. J Phycol 31:778-785 
Lin S, Carpenter EJ (1996) An empirical protocol for whole cell immunofluorescence of marine phytoplankton. J Phycol 32:1083-1094

Lin S, Carpenter EJ, Chang J (1996) Detection of p34cdc2and cyclin B-like proteins in Dunaliella tertiolecta. Mar Biol 125:603-610

Lin S, Chang J, Carpenter EJ (1994) Detection of proliferating cell nuclear antigen analog in four species of marine phytoplankton. J Phycol 30:449-456

Lin S, Chang J, Carpenter EJ (1995) Growth characteristics of phytoplankton determined by cell cycle proteins. 1 . PCNA immunostaining on Dunaliella tertiolecta (Chlorophyceae). J Phycol 31:338-345

McDuff RE, Chisholm SW (1982) The calculation of in situ growth rates of phytoplankton populations from fractions of cells undergoing mitosis: a clarification. Limnol Oceanogr 27:783-788

Mitchison JM (1971) The biology of the cell cycle. Cambridge University Press, London

Murray A, Hunt T (1993) The cell cycle: an introduction. Oxford University Press, New York

Olson RJ, Vaulot D. Chisholm SW (1986) Effects of environmental stress on the cell cycle of two marine phytoplankton species. Pl Physiol 80:918-925

Rodriguez M, Cho JW, Sauer HW, Rizzo PJ (1993) Evidence of the presence of a cdc2-like protem kinase in the dinoflagellate Crypthecodinıum cohniı. J Eukaryot Microbiol 40:91-96

Sasaki K, Kurose A, Ishika Y, Matsuta M (1994) Estimation of S-phase fraction in tumor tissue sections by immunohisto-

This note was submitted to the editor chemical staining of PCNA.J Histochem Cytochem 42 957-960

Swift E, Durbin EG (1972) The phased division and cytological characteristics of Pyrocystis spp. can be used to estimate doubling times of their populations in the sea. Deep Sea Res 19:189-198

Swift E. Stuart M, Meunier V (1976) The in situ growth rates of some deep-living oceanic dinoflagellates: Pyrocystis fusiformis and Pyrocystis noctiluca. Limnol Oceanogr 21: 418-426

Takahashi M (1966) Theoretical basis for cell cycle analysis. I Labelled mitosis wave method. J Theoret Biol 13:202-211

Van Bleijswijk JDL, Veldhuis MJW (1995) In situ gross growth rates of Emiliania huxleyi in enclosures with different phosphate loadings revealed by diel changes in DNA content. Mar Ecol Prog Ser 121:271-277

Van Dolah FM, Leighfield TA, Sandel HD, Hsu CK (1995) Cell division in the dinoflagellate Gambierdiscus toxicus is phased to the diurnal cycle and accompanied by activation of the cell cycle regulatory protein, $\mathrm{CDC} 2$ kinase. J Phycol 31:395-400

Vaulot D (1992) Estimate of phytoplankton division rates by the mitotic index method: the $f_{\max }$ approach revisited. Limnol Oceanogr 37:644-649

Vaulot D, Marie D. Olson RJ, Chisholm SW (1995) Growth of Prochlorococcus, a photosynthetic prokaryote, in the equatorial Pacific Ocean. Science 268:1480-1482

Yamaguchi M (1992) DNA synthesis and the cell cycle in the noxious red-tide dinoflagellate Gymnodinium nagasakiense. Mar Biol 112:191-198

Manuscript first received: November 11, 1996 Revised version accepted: March 12, 1997 